\title{
Different substrate-dependent transition states in the active site of the ribosome
}

\author{
Stephan Kuhlenkoetter ${ }^{1}$, Wolfgang Wintermeyer ${ }^{1}$ \& Marina V. Rodnina ${ }^{1}$
}

The active site of the ribosome, the peptidyl transferase centre, catalyses two reactions, namely, peptide bond formation between peptidyl-tRNA and aminoacyl-tRNA as well as the release-factordependent hydrolysis of peptidyl-tRNA. Unlike peptide bond formation, peptide release is strongly impaired by mutations of nucleotides within the active site, in particular by base exchanges at position A2602 (refs 1, 2). The 2'-OH group of A76 of the peptidyl-tRNA substrate seems to have a key role in peptide release $^{3}$. According to computational analysis ${ }^{4}$, the $2^{\prime}-\mathrm{OH}$ may take part in a concerted 'proton shuttle' by which the leaving group is protonated, in analogy to similar current models of peptide bond formation $^{4-6}$. Here we report kinetic solvent isotope effects and proton inventories (reaction rates measured in buffers with increasing content of deuterated water, $\mathrm{D}_{2} \mathrm{O}$ ) of the two reactions catalysed by the active site of the Escherichia coli ribosome. The transition state of the release factor 2 (RF2)-dependent hydrolysis reaction is characterized by the rate-limiting formation of a single strong hydrogen bond. This finding argues against a concerted proton shuttle in the transition state of the hydrolysis reaction. In comparison, the proton inventory for peptide bond formation indicates the rate-limiting formation of three hydrogen bonds with about equal contributions, consistent with a concerted eightmembered proton shuttle in the transition state $\mathrm{s}^{5}$. Thus, the ribosome supports different rate-limiting transition states for the two reactions that take place in the peptidyl transferase centre.

Peptide bond formation and peptide release involve the attack of different nucleophilic groups on the ester carbonyl carbon of peptidyltransfer (t)RNA in the P site of the ribosome; these nucleophilic groups are respectively the $\alpha$-amino group of A-site-bound aminoacyl-tRNA and a water molecule. Unlike peptide bond formation, which does not require auxiliary factors, peptide release is assisted by termination (release) factors; in E. coli, these are RF1 and RF2. On recognition of a stop codon in the decoding site, the conserved GGQ motif of RF1/2 is inserted into the peptidyl transferase centre, augmenting the active site and inducing the hydrolysis of peptidyl-tRNA (see ref. 3 for a review). Release-factor binding induces a conformational change that involves conserved $23 \mathrm{~S}$ ribosomal RNA residues, in particular U2506 and $\mathrm{U} 2585$ (refs 6-10), and opens the active site for the access of water ${ }^{11}$. The conserved Gln residue in RF1/2 has been attributed an essential function in positioning the hydrolytic water molecule and accounts for the high specificity of the active site for water as the nucleophile, discriminating against a larger amine ${ }^{12}$. Computational analysis suggested that the $2^{\prime}-\mathrm{OH}$ of A76 of the P-site tRNA may take part in a concerted proton shuttle mechanism for the protonation of the leaving $3^{\prime}-\mathrm{O}$ (ref. 4), in analogy to the mechanism suggested for peptide bond formation ${ }^{5,13}$. A fully concerted proton shuttle would involve the formation of several (two to three) strong hydrogen bonds in the transition state. This should lead to a kinetic solvent isotope effect (KSIE) and a nonlinear proton inventory. As pertinent experimental data are lacking, we have determined the KSIE for both RF2-catalysed and uncatalysed reactions by measuring reaction rates in $\mathrm{H}_{2} \mathrm{O}$ - and $\mathrm{D}_{2} \mathrm{O}$-containing buffers.
At saturation with $\mathrm{RF} 2$, the hydrolysis reaction in $\mathrm{H}_{2} \mathrm{O}$ proceeded with a catalytic rate constant $\left(k_{\text {cat }}\right)$ of about $2 \mathrm{~s}^{-1}$ (Fig. 1a). Reactions in $\mathrm{D}_{2} \mathrm{O}$ were found to be about four times slower than in $\mathrm{H}_{2} \mathrm{O}$ for both the RF2-catalysed reaction on the ribosome and the uncatalysed reaction (Fig. 1b). The magnitude of the KSIE indicates that it is a primary effect-that is, it arises from proton transfer(s) between groups that take part in the reaction directly ${ }^{14,15}$. In keeping with this contention, the same reaction rates were observed regardless of whether ribosome complexes in $\mathrm{D}_{2} \mathrm{O}$ buffer were mixed with $\mathrm{RF} 2$ in $\mathrm{H}_{2} \mathrm{O}$ buffer or vice versa (data not shown), establishing that the intrinsic reactivity of ribosomes and RF2 was not influenced by $\mathrm{H}-\mathrm{D}$ exchange.

The proton inventory showed a linear relationship for the RF2dependent reaction (Fig. 2a). This is consistent with a model in which the reaction rate is limited by the formation of a single strong hydrogen bond (a low-barrier hydrogen bond) ${ }^{14,15}$. A model involving two
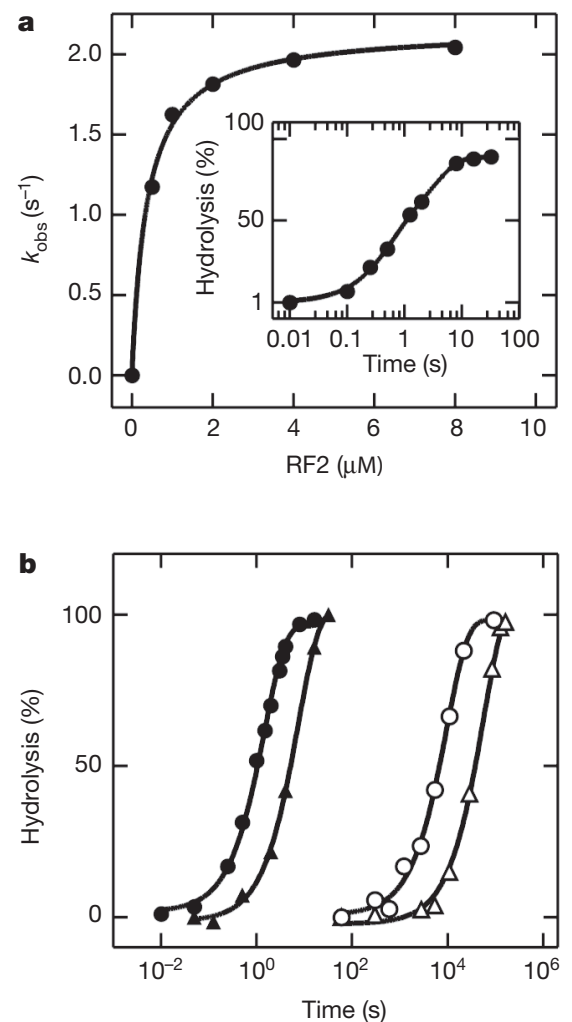

Figure $1 \mid$ RF2-catalysed hydrolysis of fMet-tRNA ${ }^{\text {fMet }}$ on the ribosome. a, Dependence on RF2 concentration. Values of the observed rate constant $\left(k_{\mathrm{obs}}\right)$ are plotted against the concentration of RF2. The value of $k_{\mathrm{obs}}$ measured at saturation equals the catalytic rate constant, $k_{\text {cat }}$. Inset, time course of hydrolysis (at $4 \mu \mathrm{M}$ RF2). b. Time courses in $\mathrm{H}_{2} \mathrm{O}$ and $\mathrm{D}_{2} \mathrm{O}$-containing buffers. Catalysed (filled symbols) and uncatalysed (open symbols) reactions were measured in buffer with either $\mathrm{H}_{2} \mathrm{O}$ (circles) or $\mathrm{D}_{2} \mathrm{O}$ (triangles).

${ }^{1}$ Max Planck Institute for Biophysical Chemistry, Am Fassberg 11, 37077 Göttingen, Germany. 

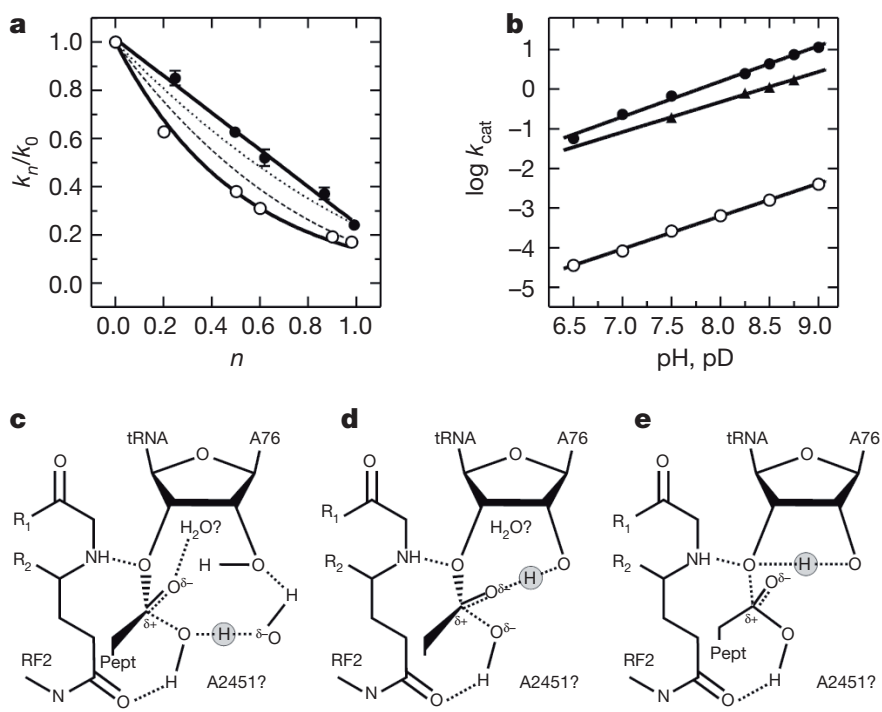

Figure $2 \mid$ KSIE and pH dependence of the hydrolysis reaction. a, Proton inventories. Time courses were measured in buffer A, pH 8.5, containing increasing mole fractions of $\mathrm{D}_{2} \mathrm{O}, n$, as indicated. Values of $k_{\text {cat }}$ measured in buffer containing only $\mathrm{H}_{2} \mathrm{O}$ and buffer containing $n$ mole fractions of $\mathrm{D}_{2} \mathrm{O}$ are $k_{0}$ and $k_{n}$, respectively. For the catalysed reaction (filled circles), the linear fit yields an overall KSIE of $4.1 \pm 0.2$; the dotted line simulates the rate-limiting simultaneous transfer of two protons in the transition-state with a fractionation factor of 0.49 each, that is, $k_{n} / k_{0}=(1-n+0.49 n)^{2}$. For the uncatalysed reaction (open circles), the curve was fitted with the function $k_{n} / k_{0}=a^{-n}$ (ref. 14 ), yielding an overall KSIE of $7.0 \pm 0.4$; the dashed line simulates the ratelimiting transfer of three protons. Standard deviations (number of experiments $\geq 3$ ) are as indicated by error bars or are smaller than the size of the symbols. b, $\mathrm{pH} / \mathrm{pD}$ dependence. Rates of the catalysed reaction were measured at varying $\mathrm{pH} / \mathrm{pD}$ in buffer $\mathrm{B}$ in $\mathrm{H}_{2} \mathrm{O}$ (filled circles) or $\mathrm{D}_{2} \mathrm{O}$ (filled triangles); the uncatalysed reaction was measured in buffer $\mathrm{B}$ in $\mathrm{H}_{2} \mathrm{O}$ (open circles). The slopes of the linear plots for the catalysed reaction were $0.89 \pm 0.03\left(\mathrm{H}_{2} \mathrm{O}\right)$ and $0.76 \pm 0.03\left(\mathrm{D}_{2} \mathrm{O}\right)$; the slope for the uncatalysed reaction was $0.83 \pm 0.02$ $\left(\mathrm{H}_{2} \mathrm{O}\right)$. $\mathbf{c}-\mathbf{e}$, Possible transition states of the catalysed reaction (see text). The single low-barrier hydrogen bond that determines the reaction rate is encircled. The possibility of the involvement of another water molecule and/or residue A2451 of $23 \mathrm{~S}$ rRNA is indicated.

equally contributing hydrogen bonds in the transition state was not compatible with the data. In contrast, the proton inventory of the uncatalysed hydrolysis reaction showed a pronounced downwards curvature, indicating the formation of more than one hydrogen bond in the transition state. The data for the latter reaction were fitted best with a model in which a large number of hydrogen bonds contribute about equally. This result is consistent with a model in which many water molecules form a hydrogen-bonded proton network facilitating the reaction.

We have also determined the $\mathrm{pH} / \mathrm{pD}$ dependence of the RF2dependent hydrolysis reaction (Fig. 2b). The plots of $\log k_{\text {cat }}$ versus $\mathrm{pH}$ or $\mathrm{pD}$ were linear up to $\mathrm{pH} 9$ with slopes of near one, suggesting that the $\mathrm{pH} / \mathrm{pD}$-dependence was determined by a single ionizing group with $\mathrm{p} K_{\mathrm{a}}>9$ (where $K_{\mathrm{a}}$ is the acid dissociation constant). The $\mathrm{pH}$ dependence of the uncatalysed hydrolysis exhibited about the same slope. For the latter reaction, the $\mathrm{pH}$-dependence reflects the ionization of either a water molecule or the $2^{\prime}-\mathrm{OH}$ of the tRNA. The same groups are directly involved in the reaction on the ribosome and are, therefore, likely to contribute to the $\mathrm{pH}$ dependence. If the ribosome or RF2 were donating additional ionizing groups, in the simplest model the slope of the $\mathrm{pH}$ dependence would increase, which is not observed. Ribosomal residues in the active site (A2451, U2585 and, in particular, A2602), the replacements of which impair peptide release ${ }^{1,2,16}$, appear to have a role in positioning the peptidyl-tRNA and/or the release factor in the active site, rather than in chemistry itself.
Substitutions of the A76 2'-OH of peptidyl-tRNA strongly inhibited peptide release by RF1, whereas the uncatalysed hydrolysis was not affected $^{3}$. Computational analysis suggests that the $2^{\prime}-\mathrm{OH}$ of A76 is essential for a proton shuttle in which the $2^{\prime}-\mathrm{OH}$ donates a proton to the leaving group (that is, the neighbouring $3^{\prime}-\mathrm{O}$ of A76 of the P-site tRNA) and, at the same time, receives one from the water attacking the carbonyl carbon ${ }^{4}$; such a mechanism implies a six-membered transition state with two hydrogen bonds of about equal contributions and two protons synchronously changing their binding partners. The concerted proton-shuttle model is not supported by the proton inventories, which clearly show that the formation of a single strong hydrogen bond in the transition state is rate-limiting. This does not exclude the possibility that at a later, not rate-limiting, step of the reaction the leaving group is protonated via a proton shuttle.

One of several mechanisms that are consistent with our data is shown in Fig. 2c. According to this model, the attacking water molecule in the transition state is engaged in a strong hydrogen bond with a hydroxide ion that facilitates proton transfer and the nucleophilic attack. Density for a water molecule in the active site was observed in the crystal structure of a complex representing the reactant state 6 . The effect of replacing the 2 '-OH group of A76 with hydrogen then may be attributed to a change of the rate-limiting step, such that proton transfer to the leaving group becomes rate-limiting. In an alternative model (Fig. 2d), the transition state may entail the attack of a hydroxide ion on the carbonyl carbon. In this case, the strong hydrogen bond could involve the 2'-OH of the P-site tRNA-which would be consistent with its important role in peptide release ${ }^{3}$ - or a water molecule donating a proton to the carbonyl oxygen. In these models, which both imply an early transition state, the transfer of other protons, including the protonation of the leaving group, does not take place in the rate-limiting step. However, a model implying a late transition state where the protonation of the leaving group is rate-limiting would also be consistent with the data (Fig. 2e). In a late transition state, the carbonyl oxygen could be unprotonated and negatively charged (as shown in Fig. 2e) or protonated; presumably, that state would form before the rate-limiting step and therefore not contribute to the proton inventories.

Our data do not exclude additional contributions to catalysis by the Gln residue of the GGQ motif, including product and transition-state stabilization, which were suggested by crystal structures of the posthydrolysis $\operatorname{state}^{7-9}$. In keeping with these suggestions, replacing the conserved Gln residue with Pro abrogated the hydrolytic activity of RF1 (ref. 9), whereas replacements with other amino acids, presenting main-chain amide groups as Gln, had only moderate effects ${ }^{17}$.

For comparison, we have examined peptide bond formation, using the reaction with puromycin ${ }^{18}$, a mimic of the $3^{\prime}$ end of aminoacyltRNA. The reaction exhibited a large KSIE of about eight, and the pronounced downward curvature of the proton inventory indicated the formation of more than one strong hydrogen bond in the transition state (Fig. 3a), indicating that the rate-limiting transition state of peptide bond formation differs from that of peptide release. The best fit to the data was obtained with a model in which three hydrogen bonds with about equal contributions are formed in the transition state, whereas a model assuming only two hydrogen bonds with equal contributions yielded a fit of significantly lower quality (Supplementary Fig. 2), disfavouring such a model; models assuming two or three hydrogen bonds with different contributions did not give satisfactory fits either (not shown). Thus, the proton inventory of peptide bond formation is consistent with a concerted proton shuttle in the transition state, supporting an eight-membered transition state, including the $2^{\prime}$-OH of the tRNA and a water molecule as proton shuttles, and three protons that move simultaneously ${ }^{4,5}$ (Fig. 3b); the model with a sixmembered transition state and only two protons 'in flight', which is not favoured by our results, is shown for comparison (Fig. 3c). Both models show early transition states, consistent with previous suggestions ${ }^{19,20}$. Late transition states are disfavoured by the kinetic isotope effect of the nucleophilic nitrogen and its near-zero Brønsted coefficient ${ }^{19}$, and 


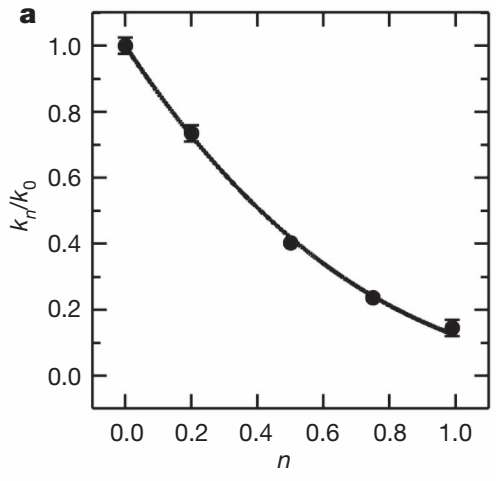

b

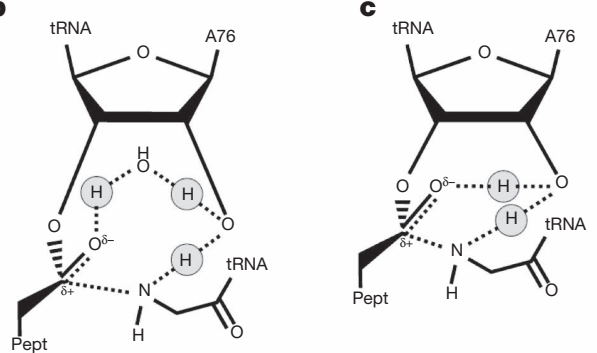

Figure $3 \mid$ KSIE of the peptidyl transfer reaction. a, Proton inventory. The puromycin (see Methods) reaction was carried out in buffer A, $\mathrm{pH} 7.5$, containing increasing mole fractions of $\mathrm{D}_{2} \mathrm{O}, n$. The same proton inventory was obtained at $\mathrm{pH} 8.5$ (not shown). The rate constant measured in $\mathrm{H}_{2} \mathrm{O}, k_{0}$, was about $0.8 \mathrm{~s}^{-1}$, that in $\mathrm{D}_{2} \mathrm{O}$ was $0.1 \mathrm{~s}^{-1}$. Standard deviations $(n \geq 3)$ are as indicated by error bars or are smaller than the symbol size. The data were fitted best with the function $k_{n} / k_{0}=(1-n+0.496 n)^{3}$, yielding an overall KSIE of $8.2 \pm 0.2$ and the rate-limiting movement of three protons with fractionation factors of 0.496 in the transition state (Supplementary Fig. 2). b, c, Transition states of peptide bond formation with eight-membered (b) or six-membered (c) proton shuttles. Hydrogen bonds involved in the respective concerted proton shuttle ${ }^{5}$ are encircled.

by recent work determining a full set of heavy-atom kinetic isotope effects (S. Strobel, personal communication). It is important to note that the ribosome does not provide groups that act as general acids or bases $^{2,21-23}$. The proton shuttles as depicted result in the protonation of the carbonyl oxygen before the less favourable protonation of the leaving $3^{\prime}$-oxygen, following previous proposals ${ }^{24,25}$.

The catalysis of peptide bond formation on the ribosome, compared with a spontaneous model reaction in solution, is entirely due to a change of the activation entropy, $\Delta S^{*}$ (ref. 26 and Supplementary Table 1). In contrast, the acceleration of peptide release caused by RF2 on the ribosome is due to a decrease of the activation enthalpy, $\Delta H^{*}$; the activation entropy, $\Delta S^{*}$, is not changed relative to the uncatalysed reaction (Table 1). Only in the case when the methyl group at Gln 252 in the GGQ motif of RF2 (a natural RF2 modification ${ }^{27}$ ) was lacking was there a significant entropic contribution, which may be attributed to water positioning through $\mathrm{Gln}^{7}$.

The present results provide strong evidence indicating that the two reactions which take place in the active site of the ribosome proceed through different transition states that are distinguished by the number

\section{Table 1 | Activation parameters}

\begin{tabular}{ccccc}
\hline & $E_{\mathrm{a}}$ & $\Delta H^{*}$ & $\Delta G^{*}$ & $\mathrm{~T} \Delta \mathrm{S}^{*}$ \\
\hline Uncatalysed & $22.5 \pm 0.8$ & $21.9 \pm 0.8$ & $23.7 \pm 0.6$ & $-1.8 \pm 0.1$ \\
RF2 & $16.5 \pm 0.6$ & $15.9 \pm 0.6$ & $18 \pm 2$ & $-1.6 \pm 0.2$ \\
RF2* & $19.8 \pm 0.7$ & $19.2 \pm 0.7$ & $18.9 \pm 0.7$ & $0.3 \pm 0.02$ \\
\hline
\end{tabular}

Activation parameters are shown for the uncatalysed and ribosome-RF2-catalysed hydrolysis reaction $\left(\mathrm{kcal} \mathrm{mol}^{-1}\right)$. They were calculated from values of $E_{\mathrm{a}}$ determined at $25^{\circ} \mathrm{C}$ in buffer A, pH 7.5. RF2* unmethylated RF2. Errors, s.d. $(n \geq 3)$ of protons 'in flight'. The rate-limiting transition state of the peptide release reaction is dominated by a single strong hydrogen bond. Ribosomal groups in the active site or residues of the release factor, including the conserved, functionally important GGQ motif, do not seem to take part in chemistry, but may play a role in positioning water molecules and stabilizing the transition state ${ }^{4,8}$. By contrast, the transition state of the peptidyl transfer reaction involves the simultaneous transfer of three protons, consistent with a concerted proton shuttle mechanism. Thus, the peptidyl transferase centre is a versatile active site, which for peptide release is augmented by residues of the release factor, providing a structured network of interactions, including ordered water molecules, that stabilizes different transition states, depending on the nature of the reactants. The catalytic mechanism employed by the ribosome illustrates how ancient RNA-world enzymes may have functioned, and how a single active site might have produced a large variety of polymers to be used as building blocks for the evolution of life.

\section{METHODS SUMMARY}

Ribosomes, initiation factors, RF2 and tRNA ${ }^{\mathrm{fMet}}$ were from E. coli. As model substrate, we have used $70 \mathrm{~S}$ initiation complexes, that is, fMet-tRNA ${ }^{\mathrm{fMet}}$ bound to ribosomes programmed with an mRNA in which the AUG start codon was immediately followed by a UAA termination codon. Hydrolysis experiments were performed with RF2 that had Ala at position 246 and was methylated at N5 of Gln 252 in the GGQ motif for higher activity of the factor ${ }^{27}$. Peptide bond formation was studied by reacting initiation complexes with puromycin ${ }^{18}$. Proton inventories were measured at least three times to achieve the necessary precision ${ }^{14,15}$.

Full Methods and any associated references are available in the online version of the paper at www.nature.com/nature.

Received 27 April; accepted 3 June 2011.

Published online 31 July 2011.

1. Polacek, N. et al. The critical role of the universally conserved A2602 of $23 \mathrm{~S}$ ribosomal RNA in the release of the nascent peptide during translation termination. Mol. Cell 11, 103-112 (2003)

2. Youngman, E. M., Brunelle, J. L., Kochaniak, A. B. \& Green, R. The active site of the ribosome is composed of two layers of conserved nucleotides with distinct roles in peptide bond formation and peptide release. Cell 117, 589-599 (2004).

3. Brunelle, J. L., Shaw, J. J., Youngman, E. M. \& Green, R. Peptide release on the ribosome depends critically on the 2' OH of the peptidyl-tRNA substrate. RNA 14, 1526-1531 (2008).

4. Trobro, S. \& Aqvist, J. Mechanism of the translation termination reaction on the ribosome. Biochemistry 48, 11296-11303 (2009).

5. Wallin, G. \& Aqvist, J. The transition state for peptide bond formation reveals the ribosome as a water trap. Proc. Natl Acad. Sci. USA 107, 1888-1893 (2010)

6. Jin, H., Kelley, A. C., Loakes, D. \& Ramakrishnan, V. Structure of the 70 S ribosome bound to release factor 2 and a substrate analog provides insights into catalysis of peptide release. Proc. Natl Acad. Sci. USA 107, 8593-8598 (2010).

7. Laurberg, M. et al. Structural basis for translation termination on the $70 \mathrm{~S}$ ribosome. Nature 454, 852-857 (2008).

8. Weixlbaumer, A. et al. Insights into translational termination from the structure of RF2 bound to the ribosome. Science 322, 953-956 (2008)

9. Korostelev, $A$. et al. Crystal structure of a translation termination complex formed with release factor RF2. Proc. Natl Acad. Sci. USA 105, 19684-19689 (2008).

10. Petry, S. et al. Crystal structures of the ribosome in complex with release factors RF1 and RF2 bound to a cognate stop codon. Cell 123, 1255-1266 (2005).

11. Schmeing, T. M., Huang, K. S., Kitchen, D. E., Strobel, S. A. \& Steitz, T. A. Structural insights into the roles of water and the 2 ' hydroxyl of the P site tRNA in the peptidyl transferase reaction. Mol. Cell 20, 437-448 (2005).

12. Shaw, J. J. \& Green, R. Two distinct components of release factor function uncovered by nucleophile partitioning analysis. Mol. Cell 28, 458-467 (2007).

13. Trobro, S. \& Aqvist, J. Analysis of predictions for the catalytic mechanism of ribosomal peptidyl transfer. Biochemistry 45, 7049-7056 (2006).

14. Quinn, D. M. in Isotope Effects in Chemistry and Biology (eds Kohen, A. \& Limbach, H. H.) 995-1018 (CRC Taylor and Francis, 2006)

15. Schowen, K. B. J. in Transition States of Biochemical Processes (eds Gandour, R. D. \& Schowen, R. L.) 225-283 (Plenum, 1972).

16. Amort, M. et al. An intact ribose moiety at A2602 of 23S rRNA is key to trigger peptidyl-tRNA hydrolysis during translation termination. Nucleic Acids Res. 35, 5130-5140 (2007)

17. Mora, L. et al. The essential role of the invariant GGQ motif in the function and stability in vivo of bacterial release factors RF1 and RF2. Mol. Microbiol. 47, 267-275 (2003).

18. Katunin, V. I., Muth, G. W., Strobel, S. A., Wintermeyer, W. \& Rodnina, M. V. Important contribution to catalysis of peptide bond formation by a single ionizing group within the ribosome. Mol. Cell 10, 339-346 (2002). 


\section{RESEARCH LETTER}

19. Kingery, D. A. et al. An uncharged amine in the transition state of the ribosomal peptidyl transfer reaction. Chem. Biol. 15, 493-500 (2008).

20. Seila, A. C., Okuda, K., Nunez, S., Seila, A. F. \& Strobel, S. A. Kinetic isotope effect analysis of the ribosomal peptidyl transferase reaction. Biochemistry $\mathbf{4 4}$, 4018-4027 (2005).

21. Beringer, M., Adio, S., Wintermeyer, W. \& Rodnina, M. The G2447A mutation does not affect ionization of a ribosomal group taking part in peptide bond formation. RNA 9, 919-922 (2003).

22. Beringer, M. et al. Essential mechanisms in the catalysis of peptide bond formation on the ribosome. J. Biol. Chem. 280, 36065-36072 (2005)

23. Bieling, P., Beringer, M., Adio, S. \& Rodnina, M. V. Peptide bond formation does not involve acid-base catalysis by ribosomal residues. Nature Struct. Mol. Biol. 13, 423-428 (2006).

24. Huang, K. S., Carrasco, N., Pfund, E. \& Strobel, S. A. Transition state chirality and role of the vicinal hydroxyl in the ribosomal peptidyl transferase reaction. Biochemistry 47, 8822-8827 (2008).

25. Rangelov, M. A., Vayssilov, G. N., Yomtova, V. M. \& Petkov, D. D. The syn-oriented 2-OH provides a favorable proton transfer geometry in 1,2-diol monoester aminolysis: implications for the ribosome mechanism. J. Am. Chem. Soc. 128, 4964-4965 (2006)
26. Sievers, A., Beringer, M., Rodnina, M. V. \& Wolfenden, R. The ribosome as an entropy trap. Proc. Natl Acad. Sci. USA 101, 7897-7901 (2004).

27. Dincbas-Renqvist, V. et al. A post-translational modification in the GGQ motif of RF2 from Escherichia coli stimulates termination of translation. EMBO J. 19 , 6900-6907 (2000)

Supplementary Information is linked to the online version of the paper at www.nature.com/nature.

Acknowledgements We thank H.-H. Limbach for discussions and advice. This work was supported by the Deutsche Forschungsgemeinschaft (M.V.R. and W.W.).

Author Contributions S.K., W.W. and M.V.R. conceived the study and designed experiments. S.K. performed experiments. All three authors discussed results and wrote the paper.

Author Information Reprints and permissions information is available at www.nature.com/reprints. The authors declare no competing financial interests. Readers are welcome to comment on the online version of this article at www.nature.com/nature. Correspondence and requests for materials should be addressed to M.V.R. (rodnina@mpibpc.mpg.de). 


\section{METHODS}

Experimental system. As model substrate for peptide release we have used fMettRNA $^{\text {fMet }}$ bound to ribosomes programmed with an mRNA in which the AUG start codon was immediately followed by a UAA termination codon ${ }^{12}$. Hydrolysis experiments were performed with RF2 that had Ala at position 246 and that was fully methylated at N5 of Gln252 in vitro for higher activity of the factor ${ }^{27}$. Measurements were performed at saturating concentrations of RF2 $(4 \mu \mathrm{M})$, where the binding of the factor does not limit the reaction rate. The $k_{\text {cat }}$ value for the RF2 dependent hydrolysis of fMet-tRNA ${ }^{\text {fMet }}$ that we obtained $\left(2.2 \mathrm{~s}^{-1}\right.$; Fig. 1a) is comparable with published $k_{\text {cat }}$ values for the hydrolysis of peptidyl-tRNA carrying peptide chains of four amino acids $\left(1.5 \mathrm{~s}^{-1}\right.$, ref. $28 ; \sim 6 \mathrm{~s}^{-1}$, ref. 27). As model substrate for peptide bond formation, $70 \mathrm{~S}$ initiation complexes were used that were programmed with a similar mRNA, except that a UUC codon followed the AUG codon. Time courses were measured with saturating concentration of puromycin $(10 \mathrm{mM})$, that is, at conditions where the chemistry step is rate-limiting ${ }^{18,26}$.

Materials. Ribosomes from E. coli MRE600, initiation factors, and $\left.\mathrm{f}^{3} \mathrm{H}\right] \mathrm{Met}-$ tRNA $^{\text {fMet }}$ were prepared as described ${ }^{18,21-23}$. The mRNAs (5'-GGCAAGGAGGU AAAUAAUGUAAACGAUU-3', initiation and stop codons underlined, or a similar mRNA with a UUC codon following the initiation codon) were purchased from CureVac. Deuterium oxide (99.95\%) was obtained from Deutero $\mathrm{GmbH} .{ }^{3} \mathrm{H}-$ labelled L-methionine and [methyl- $\left.{ }^{3} \mathrm{H}\right] \mathrm{S}$-adenosyl-L-methionine were from Hartmann Analytics.

Initiation complexes. Ribosomes $(1.5 \mu \mathrm{M})$, mRNA $(3 \mu \mathrm{M}), \mathrm{f}\left[{ }^{3} \mathrm{H}\right] \mathrm{Met}^{-\mathrm{tRNA}}{ }^{\mathrm{fMet}}$ $(2.7 \mu \mathrm{M})$, initiation factors 1,2 and $3(1.8 \mu \mathrm{M}$ each) and GTP $(1 \mathrm{mM})$ in a total volume of $6.4 \mathrm{ml}$ were incubated for $30 \mathrm{~min}$ at $37^{\circ} \mathrm{C}$. Complexes were subsequently purified by ultracentrifugation, where $1.6 \mathrm{ml}$ of the reaction mixture were centrifuged through a $400 \mu \mathrm{l}$ sucrose cushion $(20 \mathrm{mM}$ HEPES- $\mathrm{HCl}, \mathrm{pH} 7.5$, $100 \mathrm{mM} \mathrm{KCl}, 20 \mathrm{mM} \mathrm{MgCl}_{2}, 40 \%$ sucrose). Pellets were resuspended in the appropriate buffer (see below). The initiation efficiency was controlled by nitrocellulose filtration and was $>95 \%$ for the complexes used for the experiments. Filters were dissolved in $10 \mathrm{ml}$ of scintillation liquid (Quickszint 361; Zinsser Analytic), and the radioactivity was determined by scintillation counting (TriCarb, Perkin Elmer).

Preparation of RF2. The RF2 gene was amplified by PCR from E. coli JM109 genomic DNA (Ala at position 246) and cloned into a pET30a vector. The T of the inner in-frame TAG stop codon of the RF2 reading frame was deleted by the quick-change method, eliminating the necessity of the +1 frameshift for RF2 expression. E. coli $\mathrm{Bl} 21$ (DE3) cells were transformed with a pET30a/RF2 construct coding for RF2 extended by a C-terminal six-histidine tag. The protein was purified by $\mathrm{Ni}^{2+}$-NTA affinity chromatography and on a HiTrap Q FF (GE Healthcare) column. The His-tag did not affect the functional activity of RF2, as verified using an untagged protein. If not stated otherwise, RF2 was $\mathrm{N}^{5}$-methylated at Gln252. For methylation in vitro, RF2 $(10 \mu \mathrm{M})$, S-adenosyl-L-methionine
$(50 \mu \mathrm{M})$ and the methyl transferase $\operatorname{HemK}(0.5 \mu \mathrm{M}$; also designated PrmC) were incubated overnight at room temperature in a total volume of $18 \mathrm{ml}$ in buffer A. Methylated RF2 was purified by gel filtration on a HiLoad 26/60 Superdex 75 column (GE Healthcare). The extent of methylation was close to $100 \%$, as analysed by filter binding of RF2 that was radioactively labelled with [methyl- $\left.{ }^{3} \mathrm{H}\right] \mathrm{S}-$ adenosyl-L-methionine or by HPLC ESI-MS.

Kinetic measurements. Experiments were carried out at $37^{\circ} \mathrm{C}$ in buffer A $(20 \mathrm{mM}$ HEPES- $\mathrm{HCl}, 100 \mathrm{mM} \mathrm{KCl}, 7 \mathrm{mM} \mathrm{MgCl} 2$ ) adjusted to $\mathrm{pH} 7.5$ or 8.5 , as indicated. For measuring $\mathrm{pH} / \mathrm{pD}$ dependencies, buffer $\mathrm{B}(50 \mathrm{mM}$ Tris- $\mathrm{HCl}, 20 \mathrm{mM}$ Bis-Tris$\mathrm{HCl}, 70 \mathrm{mM} \mathrm{NH}_{4} \mathrm{Cl}, 30 \mathrm{mM} \mathrm{KCl}, 7 \mathrm{mM} \mathrm{MgCl}_{2}$ ) was used. Time courses of RF2catalysed $\left.\mathrm{f}^{3} \mathrm{H}\right] \mathrm{Met}^{\mathrm{TRNA}} \mathrm{R}^{\mathrm{fMet}}$ hydrolysis on the ribosome were started by rapidly mixing equal volumes $(14 \mu \mathrm{l})$ of initiation complex $(0.5 \mu \mathrm{M})$ and RF2 $(8 \mu \mathrm{M})$ in a quench-flow apparatus (KinTek Corp). Reactions were terminated by TCA precipitation, and remaining intact $\mathrm{f}\left[{ }^{3} \mathrm{H}\right]$ Met-tRNA ${ }^{\mathrm{fMet}}$ was collected on nitrocellulose filters and quantified by scintillation counting. Time courses of the uncatalysed reaction, measured with $\mathrm{f}\left[{ }^{3} \mathrm{H}\right] \mathrm{Met}-\mathrm{tRNA}{ }^{\mathrm{fMet}}$ free in solution, were started by manual mixing. For determining the $\mathrm{pH}$ dependence, it was verified that the concentration of RF2 used was saturating over the whole $\mathrm{pH}$ range (data not shown). Time courses of peptide bond formation were measured in buffer A (pH 7.5 and 8.5$)$ by rapidly mixing equal volumes of the respective initiation complexes $(0.5 \mu \mathrm{M})$ and puromycin $(20 \mathrm{mM})$. The reaction was stopped and the remaining intact $\left.\mathrm{f}^{3} \mathrm{H}\right]$ Met-tRNA ${ }^{\mathrm{fMet}}$ quantified as described above.

Determination of activation parameters. Activation energies $\left(E_{\mathrm{a}}\right)$ were determined from the slopes of the Arrhenius plots (Supplementary Fig. 1), which yielded $-E_{\mathrm{a}} / R$. The enthalpy of activation was calculated as $\Delta H^{*}=E_{\mathrm{a}}-R T$, where $R$ is the gas constant $\left(1.9872 \mathrm{cal} \mathrm{K}^{-1} \mathrm{~mol}^{-1}\right)$ and $T$ the temperature $\left(298.15^{\circ} \mathrm{K}\right)$. Free energies of activation were calculated from $\Delta G^{*}=-R T$ $\ln \left[\left(k_{\text {cat }} h\right) /\left(k_{\mathrm{B}} T\right)\right]$, where $h$ is Planck's constant and $k_{\mathrm{B}}$ is Boltzmanńs constant. $T \Delta S^{*}$ was calculated as the difference between $\Delta G^{*}$ and $\Delta H^{*}$

Determination of kinetic solvent isotope effects. The KSIE was determined by comparing reaction rates in $\mathrm{H}_{2} \mathrm{O}$ - and $\mathrm{D}_{2} \mathrm{O}$-containing buffer. Buffers were prepared with $\mathrm{D}_{2} \mathrm{O}$, and the $\mathrm{pD}$ (negative logarithm of $\left[\mathrm{D}^{+}\right]$) was adjusted taking into account the 0.4 unit shift for glass electrode measurements in $\mathrm{D}_{2} \mathrm{O}$ (ref. 29), which ensures equal concentrations of $\mathrm{OD}^{-}$and $\mathrm{OH}^{-}$in $\mathrm{D}_{2} \mathrm{O}$ and $\mathrm{H}_{2} \mathrm{O}$, respectively. Initiation complexes were prepared and purified in buffers with the desired $\mathrm{H}_{2} \mathrm{O}$ / $\mathrm{D}_{2} \mathrm{O}$ ratio. $\mathrm{RF} 2$ was dialysed overnight at $4{ }^{\circ} \mathrm{C}$ into the $\mathrm{D}_{2} \mathrm{O}$-containing buffers using dialysis cassettes ( $10 \mathrm{kDa}$ molecular weight cut-off; Pierce). Proton inventories were measured at least three times to achieve the necessary precision ${ }^{14,15}$.

28. Freistroffer, D. V., Kwiatkowski, M., Buckingham, R. H. \& Ehrenberg, M. The accuracy of codon recognition by polypeptide release factors. Proc. Natl Acad. Sci. USA 97, 2046-2051 (2000).

29. Glasoe, P. K. \& Long, F. A. Use of glass electrodes to measure acidities in deuterium oxide. J. Phys. Chem. 64, 188-190 (1960). 